\begin{tabular}{|c|c|c|}
\hline \multirow{2}{*}{$\begin{array}{r}\text { Case Reports in } \\
\text { Gastroenterology }\end{array}$} & \multicolumn{2}{|c|}{ Case Rep Gastroenterol 2020;14:91-97 } \\
\hline & $\begin{array}{l}\text { DOI: } 10.1159 / 000506183 \\
\text { Published online: February 20, } 2020\end{array}$ & $\begin{array}{l}\text { (C) } 2020 \text { The Author(s) } \\
\text { Published by S. Karger AG, Basel } \\
\text { www.karger.com/crg }\end{array}$ \\
\hline & $\begin{array}{l}\text { This article is licensed under the } \\
\text { International License (CC BY-NC) } \\
\text { Usage and distribution for commercia }\end{array}$ & $\begin{array}{l}\text { mons Attribution-NonCommercial } 4.0 \\
\text { rger.com/Services/OpenAccessLicense). } \\
\text { quires written permission. }\end{array}$ \\
\hline
\end{tabular}

\title{
Right Hemihepatectomy via an Anterior Approach for Hepatocellular Carcinoma in a Situs Inversus Totalis Patient
}

\author{
Rong-Dang Fu, ${ }^{a}$ Jie-Yuan $\mathrm{Li}^{\mathrm{b}} \quad$ Xiao-Hong Zhang ${ }^{\mathrm{a}}$ Huan-Wei Chen ${ }^{\mathrm{b}}$ \\ aDepartment of Infectious Diseases, the Third Affiliated Hospital of Sun Yat-sen \\ University, Guangzhou, China; ${ }^{b}$ Department of Hepatic Surgery, the Affiliated Foshan \\ Hospital of Sun Yat-sen University, Foshan, China
}

\section{Keywords}

Situs inversus totalis · Hepatocellular carcinoma - Anterior approach · Hepatectomy · Liver · Case report

\begin{abstract}
Situs inversus totalis (SIT) is a rare congenital condition in which the usual position of the organs is reversed from left to right as a mirror image of the normal situation. Due to the abnormal transposition, this represents a technical challenge for the surgeon. In the present study, right hemihepatectomy via the anterior approach was performed for a 68-year-old hepatocellular carcinoma (HCC) patient with SIT. SIT was diagnosed by chest X-ray and computed tomography. The tumors were located in segments VIII and VI of the liver, and there was no metastasis to the lymph nodes and distant organs. Hemihepatic vascular inflow occlusion was performed using the selective intra-Glissonian approach. The middle hepatic vein was preserved under the guidance with intraoperative ultrasonography. The present case suggests that right hemihepatectomy via the anterior approach may be a safe, feasible, and effective procedure for HCC patients with SIT.




\section{Case Reports in Gastroenterology}

Case Rep Gastroenterol 2020;14:91-97

DOI: $10.1159 / 000506183$

(c) 2020 The Author(s). Published by S. Karger AG, Basel www.karger.com/crg

Fu et al.: Right Hemihepatectomy via an Anterior Approach for Hepatocellular Carcinoma in a Situs Inversus Totalis Patient

\section{Introduction}

Situs inversus totalis (SIT) is a rare congenital condition in which the usual position of the organs is reversed from left to right as a mirror image of the normal condition. The incidence rate of SIT ranges from 1:5,000 to 1:10,000 [1]. Due to the mirror displacement of the abdomen and chest organs, it represents a technical challenge for the surgeon. In 1983, Kanematsu et al. [2] described the first case of a hepatocellular carcinoma (HCC) patient with SIT who underwent open right hepatic lobectomy. Ranucci et al. [3] reported a 52-year-old man with SIT who received resection of segments VII and V with the intermittent Pringle maneuver. The present report described how right hemihepatectomy via the anterior approach was performed in an SIT patient with HCC and assessed its safety and efficacy.

\section{Case Presentation}

A 68-year-old man with SIT was admitted to the Affiliated Foshan Hospital of Sun Yat-sen University for the diagnosis of HCC. SIT was diagnosed via chest X-ray and computed tomography (CT). The upper-abdominal enhanced CT scan revealed two high-density areas $(36 \times 31$ $\mathrm{mm}$ and $8 \times 7 \mathrm{~mm}$, respectively) in segment VIII (Fig. 1) and one high-density area (5 $\times 5 \mathrm{~mm})$ in segment VI (Fig. 2) of the liver. The laboratory and auxiliary examination revealed that the hepatitis B virus marker was positive and that the alpha-fetoprotein expression level was 81 $\mathrm{ng} / \mathrm{mL}$. Furthermore, there were no ascites or extrahepatic lymph nodes in the liver. The indication for hepatectomy and the procedure options were based on the tumor location, remnant liver volume, and the hepatic functional reserve assessed by the Model for End-Stage Liver Disease (MELD) score, the indocyanine green retention rate at 15 min (ICG-R15), and Child-Pugh classification. The patient presented with preserved liver function (Child A, ICGR15: 3.8\%), and was considered as a good candidate for right hemihepatectomy after a multidisciplinary meeting. Selective hemihepatic vascular inflow occlusion via the intra-Glissonian approach was used to control the hepatic blood flow (Fig. 3a, b). Intraoperative ultrasound (IOUS) was used to locate the position of the middle hepatic vein (MHV). Then, along the actual ischemic line of the right liver (Fig. 3c), the hepatic parenchyma transection from the surface of the liver parenchyma to the superficial layer of the vena cava was performed using an ultrasound scalpel and by bipolar electrocoagulation (Fig. 3d). Afterwards, the right hepatic vein was disconnected and sutured. Mobilization was performed after the right liver was completely separated from the inferior vena cava, and the coronary and triangular ligaments were divided. The pathology revealed moderate differentiation of HCC, and the liver tissues presented with cirrhosis. The patient was discharged on postoperative day 10 , and there was no tumor recurrence during the 2-year follow-up period.

\section{Discussion}

Patients with SIT have no pathophysiological significance but pose technical challenges for the hepatic surgeons due to the complete mirror-image anatomy and the possible associated vascular and hepatobiliary abnormalities, especially when underlying liver cirrhosis is present [4]. In the present case, there was no vascular or hepatobiliary abnormalities in preoperative auxiliary examination. Patel et al. [5] reported a 49-year-old woman with SIT who had a $12 \times 11 \times 9 \mathrm{~cm}$ sized HCC in segments VII and VIII and received right hepatectomy. In 


\section{Case Reports in Gastroenterology}

Case Rep Gastroenterol 2020;14:91-97

DOI: $10.1159 / 000506183$

(c) 2020 The Author(s). Published by S. Karger AG, Basel www.karger.com/crg

Fu et al.: Right Hemihepatectomy via an Anterior Approach for Hepatocellular Carcinoma in a Situs Inversus Totalis Patient

addition, they also reviewed 12 cases related to HCC patients with SIT between 1983 to 2012, which included 10 cases from Japan and 2 cases from China [5]. In 2017, Hong et al. [6] described a HCC patient with SIT who received pure laparoscopic right hepatectomy. The present study reports a 68-year-old male HCC patient with SIT who received right hemihepatectomy via the anterior approach. To the best of our knowledge, this is the first study that reported a right hemihepatectomy via the anterior approach for a HCC patient with SIT.

Right hepatectomy via the anterior approach, without the mobilization of the liver, is an alternative option for the treatment of HCC patients [7]. This technique includes initial vascular inflow control, completion of the parenchymal transection, and venous outflow control, before the right liver is mobilized. Accumulating evidence suggests that the technique of the anterior approach favors the surgical and long-term survival outcomes of HCC patients who received major right hepatectomy for large HCCs, when compared to patients who received this using the conventional approach. In addition, a prospective study conducted by Hao et al. [8] revealed that the prognosis of HCC patients who underwent hepatectomy using the anterior approach was superior to that for patients who received this using the conventional approach, suggesting that tumor size $(>5 \mathrm{~cm})$ could be the clinical indicator for the anterior approach for hepatectomy. In the present case, multiple liver tumors with a size smaller than 5 $\mathrm{cm}$ were detected in the right liver. However, it is possible that this does not meet the above requirements. Furthermore, since HCC is a soft and friable tumor, vascular invasion is very common. Therefore, in order to reduce the intraoperative shedding of tumor cells in the vessels and improve the long-term survival of the present patient, the investigators performed a right hemihepatectomy via the anterior approach.

The MHV is located in the middle hepatic fissure and drains the bloodstream of segments IV, V, and VIII. Hence, right hemihepatectomy with MHV excision may lead to the venous backflow obstruction of segment IV. Therefore, MHV preservation and reconstruction were performed to preserve the vein perfusion and avoid congestion [9]. Hemihepatectomy guided by MHV has the potential to achieve an adequate tumor-free resection margin while preserving venous drainage and functional liver tissues, which may result in a higher tumor-free survival rate [10]. Therefore, the MHV should be preserved or reconstructed whenever possible during hepatic hemihepatectomy [11]. In the present case, the patient presented with liver cirrhosis. Therefore, the investigators decided to preserve the MHV to avoid congestion in the remnant liver and postoperative hepatic insufficiency. IOUS has been considered as an essential adjunct in hepatic resection. This can provide precise information about the location of the liver lesions and their association with vital anatomical structures, thereby helping guide the surgical strategy [12]. The use of the IOUS offers a chance of cure to an increasing proportion of patients who were considered only for palliative care a few years ago [13]. IOUS directly alters the preoperative surgical plan by approximately $17 \%$ [12]. Previous reports have indicated that it would be very beneficial to switch the scanning of the ultrasonic probe from normal to inverse modality, in order to display the usual appearance of the intrahepatic anatomy of a patient with SIT on the screen [3]. For the present case, the MHV was preserved under the guidance of IOUS.

In conclusion, pre-operation multidisciplinary evaluation and an adequate choice of surgical strategy are essential to ensure the safe operation for HCC patients with SIT. The present results indicated that right hemihepatectomy via the anterior approach may be a safe, feasible, and effective procedure, which may be favored for the long-term outcomes of HCC patients with SIT. 


\section{Case Reports in Gastroenterology}

\section{Statement of Ethics}

Informed consent was obtained for this case report.

\section{Disclosure Statement}

The authors have no conflicts of interest to declare.

\section{Funding Sources}

This study was funded by Medical Science and Technology Research Fund of Guangdong Province of China (A2017387).

\section{Author Contributions}

R.-D.F., J.-Y.L., and H.-W.C. were the patient's surgeons; R.-D.F. and J.-Y.L. reviewed the literature and contributed to manuscript drafting; H.-W.C. and X.-H.Z. reviewed the literature and were responsible for the revision of the manuscript for important intellectual content; all authors confirmed the final approval of the version to be submitted.

\section{References}

1 Fishman LN, Lavine JE. What's wrong when it isn't right: situs inversus and genetic control of organ position. Hepatology. 1994 Jan;19(1):257-8.

2 Kanematsu T, Matsumata T, Kohno H, Sugimachi K, Inokuchi K. Hepatocellular carcinoma with situs inversus. Cancer. 1983 Feb;51(3):549-52.

3 Ranucci G, Ardito F, Silvestrini N, Grieco A, Giuliante F. Liver resection for hepatocellular carcinoma in patient with situs inversus viscerum. Updates Surg. 2014 Mar;66(1):91-2.

4 Lee HK, Cho KB, Kim ES, Park KS. Gastrostomy in a patient with situs inversus totalis. Clin Endosc. 2013 Nov;46(6):662-5.

5 Patel RB, Gupta NR, Vasava NC, Khambholja JR, Chauhan S, Desai A. Situs Inversus Totalis (SIT) with Hepatocellular Carcinoma (HCC): A Rare Case Report and Review of 12 Other Cases. Indian J Surg. 2013 Dec;75(6):424-9.

6 Hong SK, Suh KS, Kim HS, Ahn SW, Yoon KC, Kim H, et al. Pure laparoscopic right hepatectomy in a patient with situs inversus totalis: A case report. Medicine (Baltimore). 2017 Aug;96(34):e7910.

7 Ariizumi SI, Nanashima A, Yamamoto M. Anterior approach in right hepatectomy. J Hepatobiliary Pancreat Sci. 2018 Jul;25(7):351-2.

8 Hao S, Fan P, Chen S, Tu C, Wan C. Anterior approach to improve the long-term outcome in patients with large-size hepatocellular carcinoma having liver resection. J Surg Oncol. 2016 Dec;114(7):872-8.

9 Sano K, Makuuchi M, Miki K, Maema A, Sugawara Y, Imamura H, et al. Evaluation of hepatic venous congestion: proposed indication criteria for hepatic vein reconstruction. Ann Surg. 2002 Aug;236(2):241-7.

10 Qiu Y, Zhu X, Zhu R, Zhou J, Zhou T, Wang Y, et al. The clinical study of precise hemihepatectomy guided by middle hepatic vein. World J Surg. 2012 Oct;36(10):2428-35.

11 Inoue Y, Suzuki Y, Ota M, Fujii K, Kawaguchi N, Shimizu T, et al. Comparison of Regeneration of Remnant Liver After Hemihepatectomy with or Without the Middle Hepatic Vein. World J Surg. 2018 Apr;42(4):110010.

12 Jrearz R, Hart R, Jayaraman S. Intraoperative ultrasonography and surgical strategy in hepatic resection: what difference does it make? Can J Surg. 2015 Oct;58(5):318-22.

13 Torzilli G, Procopio F. State of the Art of Intraoperative Ultrasound in Liver Surgery: Current Use for Resection-guidance. Chirurgia (Bucur). 2017 May-Jun;112(3):320-5. 


\section{Case Reports in Gastroenterology}

\begin{tabular}{l|l}
\hline Case Rep Gastroenterol 2020;14:91-97 \\
\hline DOI: 10.1159/000506183 & $\begin{array}{l}\text { @ } 2020 \text { The Author(s). Published by S. Karger AG, Basel } \\
\text { www.karger.com/crg }\end{array}$ \\
\hline
\end{tabular}
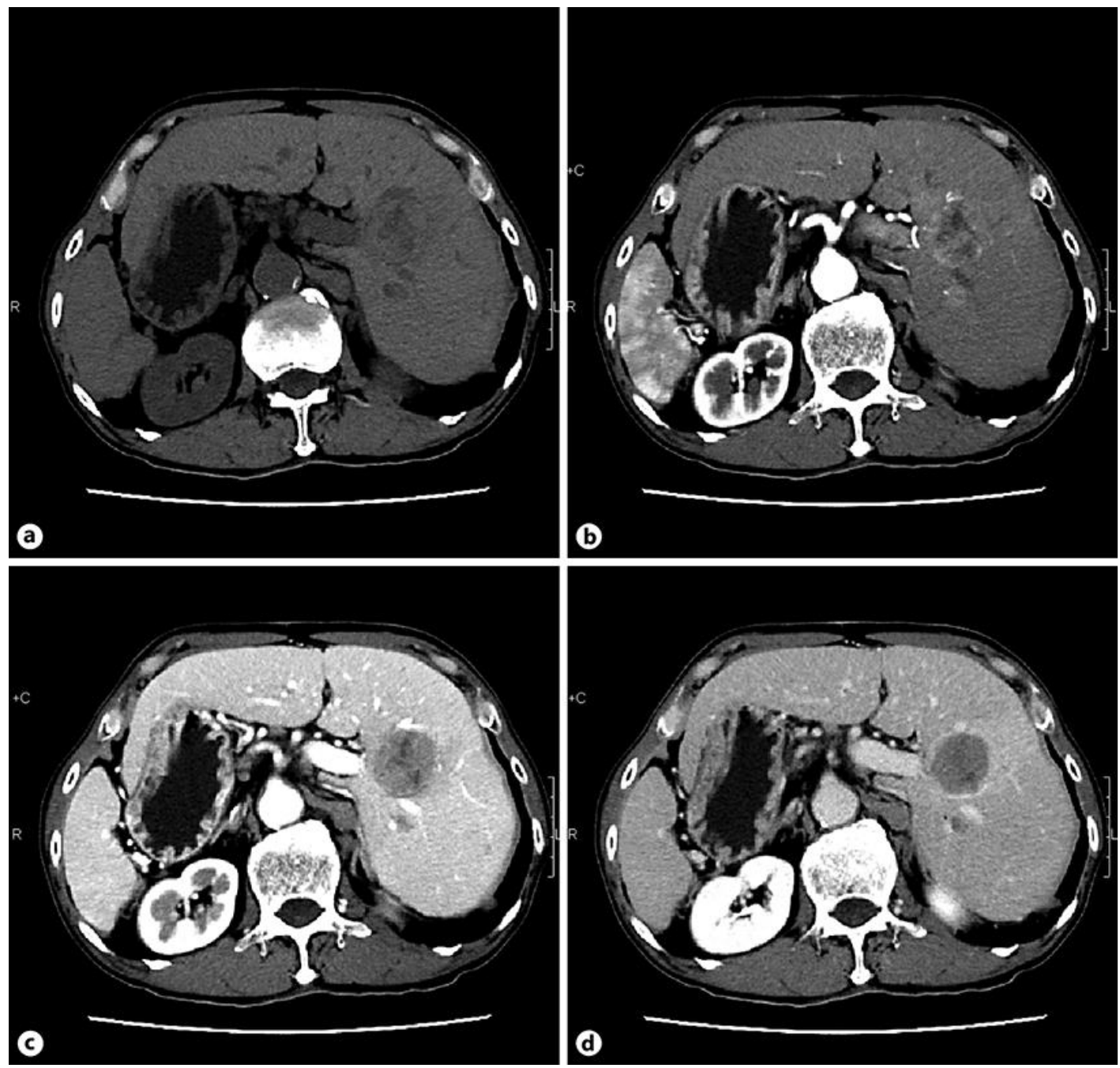

Fig. 1. Preoperative enhanced CT presents two of the $36 \times 31 \mathrm{~mm}$ and $8 \times 7 \mathrm{~mm}$ sized masses at segment VIII. a Plain scan phase. b Arterial phase. c Portal phase. $\mathbf{d}$ Delayed phase.

Fu et al.: Right Hemihepatectomy via an Anterior Approach for Hepatocellular Carcinoma in a Situs Inversus Totalis Patient 


\section{Case Reports in Gastroenterology}

\begin{tabular}{l|l}
\hline Case Rep Gastroenterol 2020;14:91-97 \\
\hline DOI: 10.1159/000506183 & $\begin{array}{l}\text { ○ 2020 The Author(s). Published by S. Karger AG, Basel } \\
\text { www.karger.com/crg }\end{array}$ \\
\hline
\end{tabular}
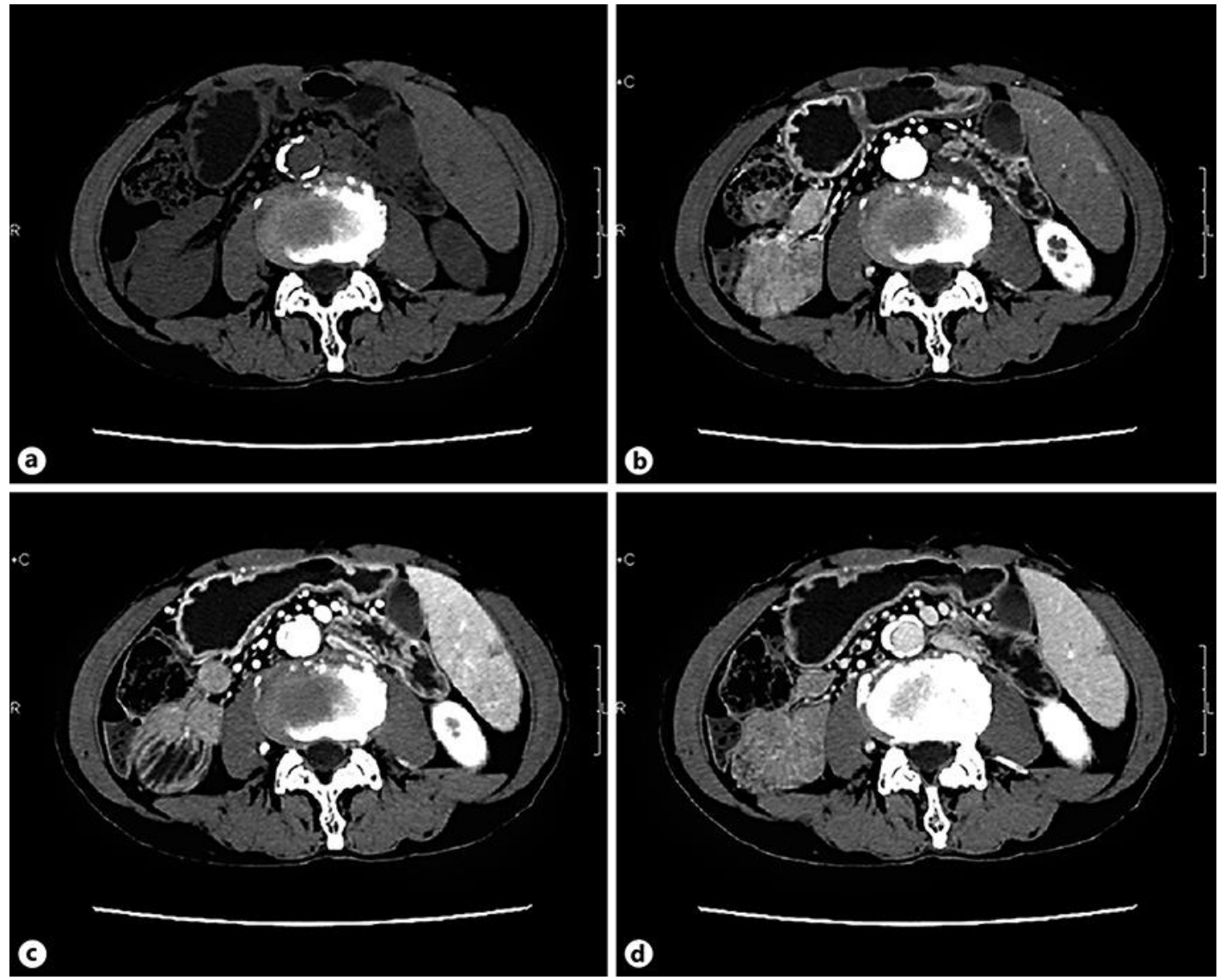

Fig. 2. Preoperative enhanced CT presents one of the $5 \times 5 \mathrm{~mm}$ sized mass at segment VI. a Plain scan phase. b Arterial phase. c Portal phase. d Delayed phase. 


\section{Case Reports in Gastroenterology}
Case Rep Gastroenterol 2020;14:91-97 DOI: $10.1159 / 000506183$
(c) 2020 The Author(s). Published by S. Karger AG, Basel www.karger.com/crg

Fu et al:: Right Hemihepatectomy via an Anterior Approach for Hepatocellular Carcinoma in a Situs Inversus Totalis Patient
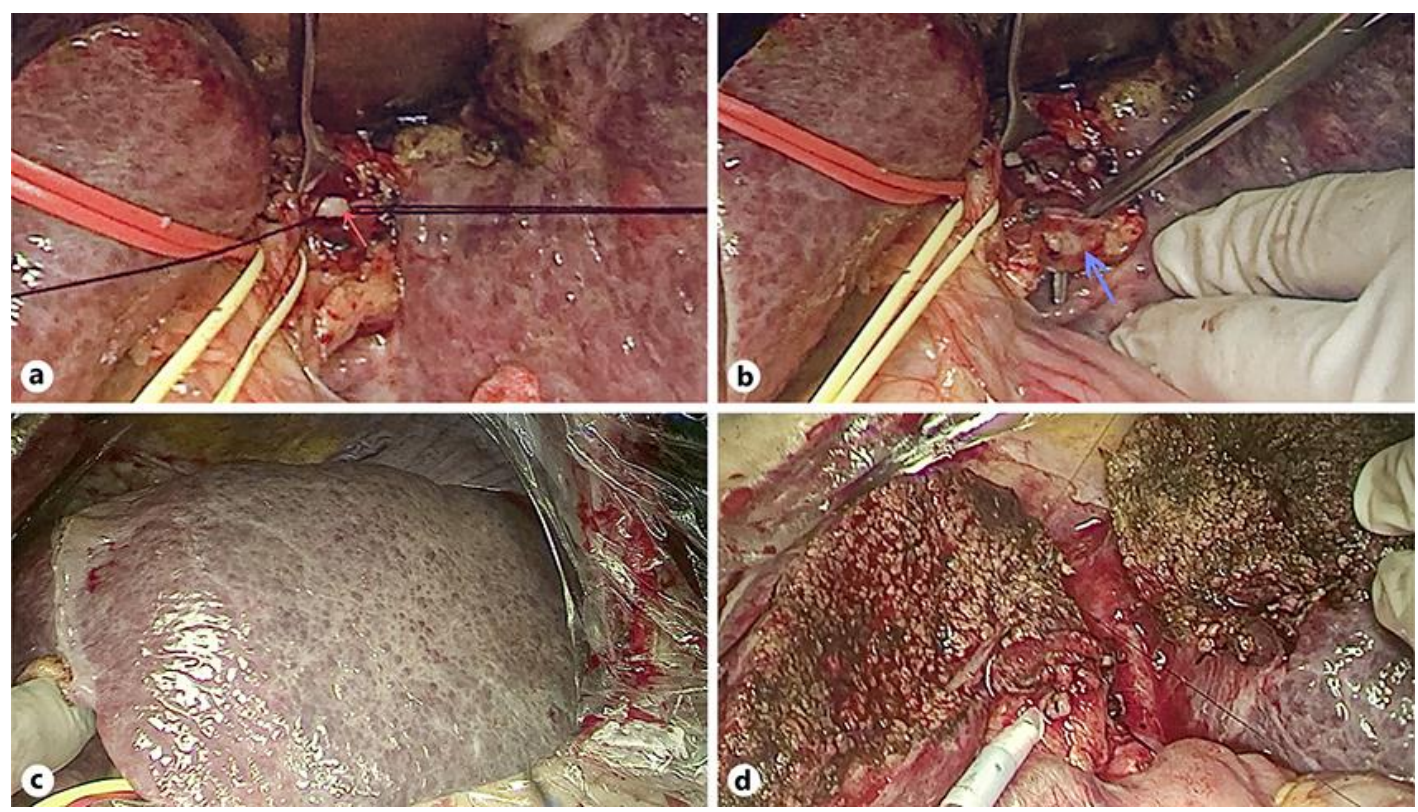

Fig. 3. Intraoperative photography of the right hemihepatectomy of HCC patients with SIT. a, b Selective isolation and ligation of the right hepatic artery ( $a$, red arrow) and right portal vein (b, blue arrow) using the intra-Glissonian approach. $\mathbf{c}$ Ischemic line of the right liver. $\mathbf{d}$ Liver cross-section before right hepatic vein disconnection. 